\title{
A rare cause of bilateral exophthalmos: about one case with a sphenoid mucocele*
}

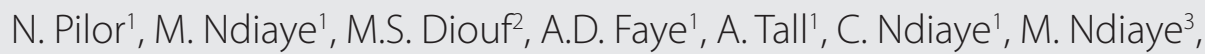 \\ R. Deguenonvo², E.S. Diom4, I.C. Ndiaye' ${ }^{1}$ R. Diouf ${ }^{2}$ \\ ' Fann University Hospital Center, Cheikh Anta Diop University, Dakar, Senegal \\ 2 HOGIP, University Hospital Center, Cheikh Anta Diop University, Dakar, Senegal \\ ${ }^{3}$ HED Hospital Center, Thies University, Thies, Senegal \\ ${ }^{4}$ Ziguinchor Hospital Center, Ziguinchor University, Ziguinchor, Senegal
}

Rhinology Online, Vol 3: 174 - 177, 2020

http://doi.org/10.4193/RHINOL/20.062

*Received for publication:

August 25, 2020

Accepted: November 2, 2020

Published: November 11, 2020

\begin{abstract}
Background: Mucocele is a benign cystic pseudo-tumor that develops within the sinus cavities. The most frequent locations are frontal and frontoethmoidal. The sphenoidal forms are rare. We report a case of sphenoidal mucocele revealed by bilateral exophthalmos.
\end{abstract}

\section{Methods and results:}

We report the case of a 14 year old male patient, without any particular pathological history, referred by his ophthalmologist for bilateral nasal obstruction, bilateral exophthalmos and visual acuity decrease evolving since one year. The ENT examination found a large, renitrant mass, filling the entire right nasal cavity. This mass pushed the nasal septum to the left. The CT scan showed a large sphenoidal, hypodense mass evoking a mucocele. The patient underwent endonasal marsupialization by endoscopic guidance.

Conclusions: Sphenoidal mucocele is a rare cause of bilateral exophthalmos. The diagnosis can be misplaced when the signs are overt extra-sinus. Hence the interest of $\mathrm{CT}$ in order to eliminate other differential dignostics.

Key words: sphenoidal mucocele, sphenoid sinus, sinus CT, sphenoidotomy, marsupialization

\section{Introduction}

Mucocele is a benign, expansive, slowly growing pseudo-cystic formation that develops within the sinus cavities. The most frequent locations are frontal and frontoethmoidal ${ }^{(1)}$. The sphenoidal forms are rare. The proximity of the orbit and the endocranon make this sphenoidal location so serious. Symptoms are often borrowed and often delayed compared to the appearance of the mucocele. We report a case of sphenoidal mucocele revealed by bilateral exophthalmos.

\section{Clinical case}

This is a 14-year-old male patient with no pathological history, referred by his ophthalmologist for bilateral nasal obstruction, bilateral proptosis and reduced visual acuity that has progressed for a year.
The ENT examination found a large, renitent mass, filling the entire right nasal cavity. It pushes back the nasal septum to the left (Figure 1).

Ophthalmologic examination found bilateral exophtalmos with bilateral optic nerve atrophy.

The CT scan showed a large sphenoidal mass, hypodense thinning its walls with mass effect on the orbital cavities, leading to bilateral exophthalmos (Figure 2 and 3).

The treatment had consisted of marsupialization of the mucocelic pocket. The approach was endonasal with optical guidance. When the mucocelic pouch was opened, puriform fluid was drained. After marsupialization, no beating possibly related to the carotid artery was observed in the murupialization cavity. A wicking of the right nasal cavity was performed at the end of the operation and maintained for 2 days. The operative consequen- 


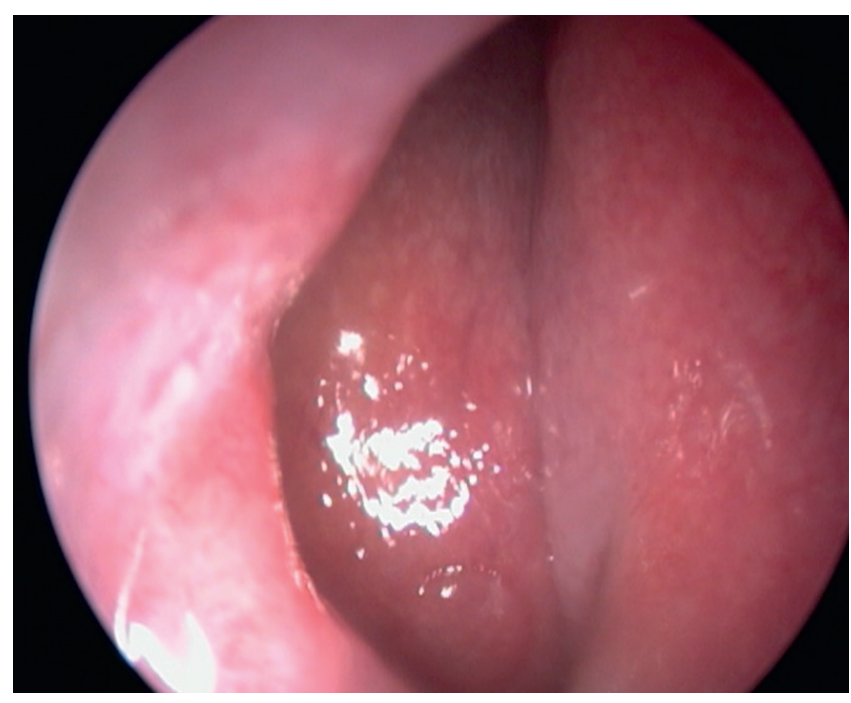

Figure 1. Mass filling the right nasal cavity.

ces were simple.

From an ophthalmological point of view, the course was marked by a regression of exophthalmos. The direct photomotor reflex was present and eye tone was normal. However, we found, on the right side, total optic nerve atrophy and on the left side a cup / disc ratio of 9/10 with loss of the foveolar reflex. The follow-up CT scan taken 4 months later showed no recurrence (Figure 4).

\section{Discussion}

The diagnosis of sphenoid sinus mucocele can be misplaced when there are overt extrinsinus signs. The exophthalmos and the decline in visual acuity, revealing in our case, lead directly to an ophthalmological pathology. It was CT that allowed the ophthalmologist to focus on the diagnosis and to be able to refer the patient to the ENT doctor. In ENT practice, sphenoid mucoceles are very rare, representing 1 to $2 \%$; the most frequent locations being the frontal and ethmoido-frontal sinuses ${ }^{(2)}$. In a series of 58 cases of mucocele, Martel-Martín reported $55 \%$ ethmodofrontal localization, 14\% pure ethmoidal localization, $24 \%$ maxillary localization and 7\% sphenoidal localization ${ }^{(1)}$.

Although rare, sphenoidal mucocele is a potentially complicated condition. The seriousness of the sphenoidal involvement lies in its close relationship with the cerebral-meningeal and orbital structures. It is a slowly evolving and expansive pathology often diagnosed at the stages of complications as in our patient: exophthalmos and optic nerve atrophy. Thus, the diagnosis must be made as soon as possible in order to prevent serious ocular complications (optic nerve compression, loss of visual acuity, blindness, mucopyocele) and neuro-meningeal ${ }^{(3,4)}$. The etiology of sphenoid sinus mucocele remains unknown, but

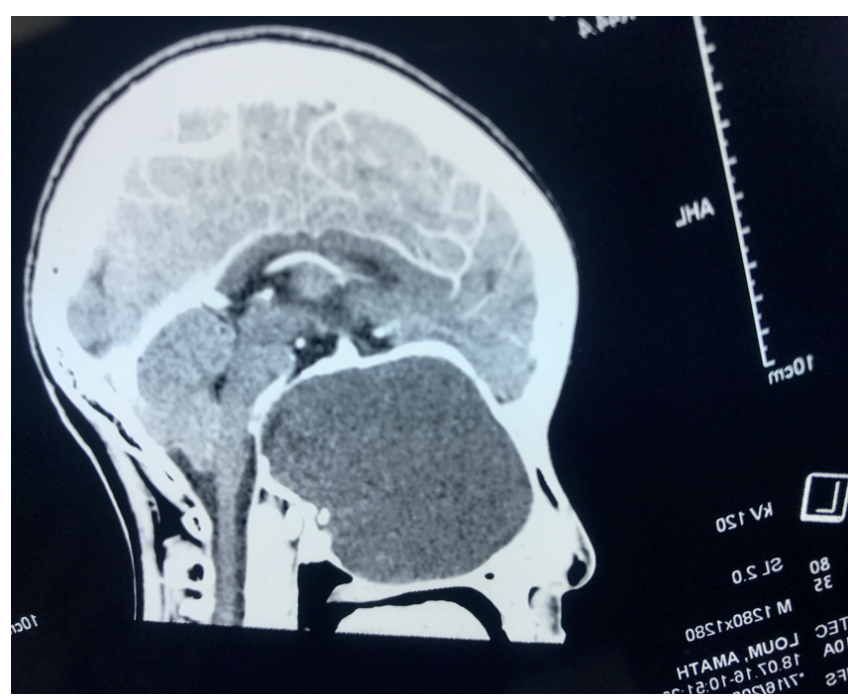

Figure 2. Sphenoid mass extending to the nasal cavity.

three pathogenic mechanisms have been formulated: submucosal edema, obstruction of the secretory duct, and obstruction of the sphenoid sinus ostium. Several contributing factors can be cited: allergic rhinitis, chronic sinusitis, polyposis, etc. ${ }^{(5)}$. Another cause to keep in mind is the radiation therapy performed for the treatment of head and neck cancers, especially nasopharyngeal cancer ${ }^{(6,7)}$. The cause of sphenoidal mucocele can also be an endonasal surgery that can cause ostial blockage ${ }^{(8)}$. In our patient, the cause remains unknown.

The diagnosis requires a tomodensitometric exploration which has a threefold interest: to make the positive diagnosis and extension, to look for anatomical varieties at risk of surgery and to look for complications. The mucocele looks like an expansive, homogeneous formation of regular contours, blowing and sometimes lysing the bone walls. Its density depends on the degree of hydration; spontaneously hypo dense or iso dense, the old forms can appear hyperdense ${ }^{(9)}$. MRI is not essential for the diagnosis of mucocele if the CT scan is clear. It is useful for looking for signs of suffering from surrounding elements, especially the eye, meninges, pituitary and optic nerve. The signal from the mucocele is variable depending on the viscosity and the protein content of the intramucocelic retention. After injection of contrast product, there is no modification of the lesion signal with peripheral enhancement ${ }^{(10)}$.

In addition, CT and MRI are important contributions in the search for differential diagnoses. The sphenoidal mucocele, however, can be confusing with nasosinus and skull base tumors.

Meningioma is a slow-growing benign tumor that is rarer in children. MRI may show a dural tail. The sphenoidal location re- 


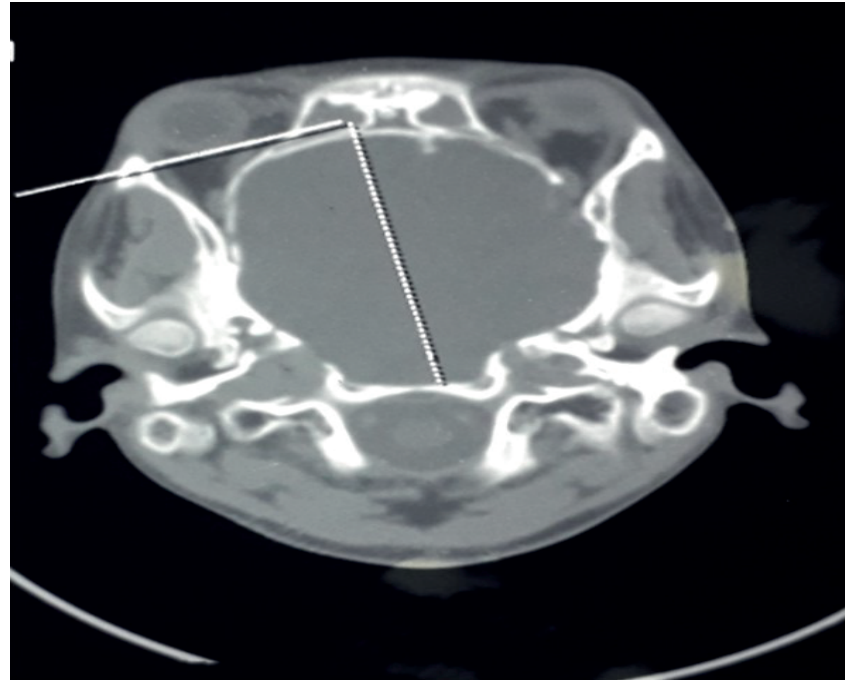

Figure 3. Sphenoid mass pushing back the eyes.

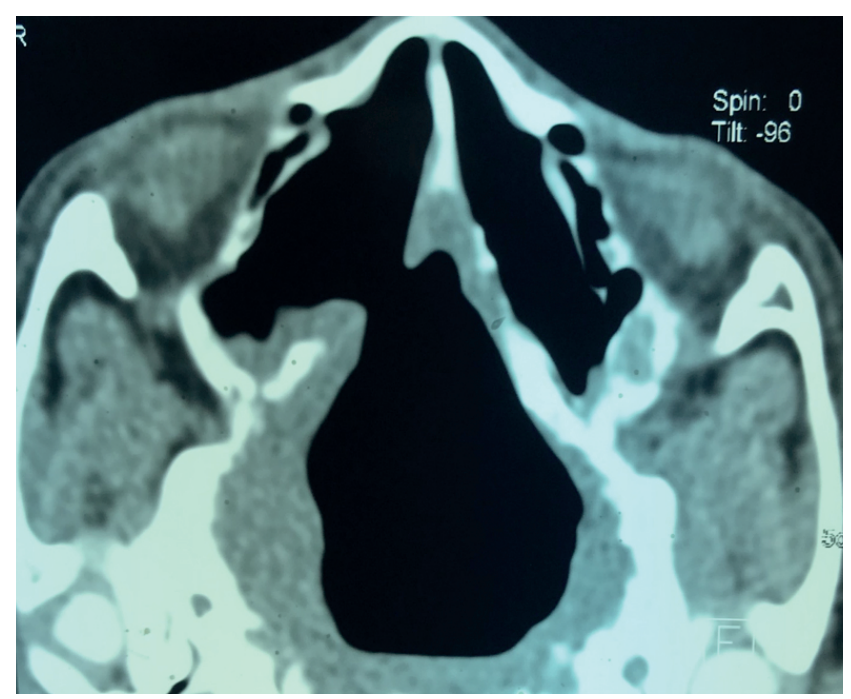

Figure 4. Postoperative control CT. presents 15 to $20 \%$ of the intracranial locations ${ }^{(11)}$. Other tumors such as hypothalamic and chiasmatic astrocytomas, fibrous dysplasia, are also differential diagnoses that should not be overlooked $^{\left({ }^{12}\right)}$. Fungal sphenoid sinusitis can take on a tumorlike appearance that can also mimic a mucocele ${ }^{(13)}$.

Ophthalmologic recovery was not complete in our patient due to the long duration of optic nerve compression. Indeed, the visual prognosis depends on the degree and duration of the optical compression but also on the speed of the surgical management ${ }^{(14)}$.

\section{Conclusions}

The sphenoid mucocele is a pseudo-cystic tumor with the potential to be aggressive towards the orbital and endocranial structures. Its borrowing symptomatology is a source of diagnostic error. Performing a CT scan is essential for a positive diagnosis. Now, the differential diagnosis of bilateral exophthalmos should include the sphenoid mucocele.

\section{Acknowledgments}

Not applicable.

\section{Authorship contribution}

NP and MN wrote the manuscript and all authors discussed the results and contributed to the final manuscript

\section{Conflict of interest}

None declared.

\section{Funding}

Not applicable.

\section{Consent for publication}

Informed consent for publication of the clinical details and images was obtained from the patient.

\section{Availability of data and materials}

Not applicable.

\section{References}

1. Martel-Martín M, Gras-Cabrerizo JR Bothe-González C, Montserrat-Gili JR De Juan-Delago M, Massegur-Solench H. Análisis clínico y resultados quirúrgicos en 58 mucoceles nasosinusales. Acta Otorrinolaringol Esp. 2015;66:92-97

2. Lee KE, Kim KS. Headache induced by the sphenoid sinus mucocele. Braz Otorhinolaryngol. 2015; 81(1):113-114.

3. Liu X, Wang $X$, Wen J, et al. Lin Chung Er Bi Yan Hou Tou Jing Wai Ke Za Zhi. 2015;29(21):1850-1852.

4. Gyawali BR, Pradhan B. Sphenoidal mucopyocele with visual impairment: case report of a rare disease and literature review. Rhinology Online. 2018; 1: 57- 59.

5. Soon SR, Lim CM, Singh $H$, et al. Sphenoid sinus mucocele: 10 cases and literature review. J Laryngol Otol. 2010;124(1): 44-47.

6. Mnejja M, Hammami B, Achour I, et al. Post-radiation mucocele in two patients treated for nasopharyngeal cancer. Cancer Radiother. 2011 ;15(3): 254-256.

7. Brunet-Garcia A, Costa-Climent MD, PujolRodríguez M, Brunet-Garcia L, Faubel-Serra M. Sphenoid sinus mucocele: an unusual complication of head and neck irradiation in a North African woman. J Clin Exp Dent. 2019:11(2):208-212.
8. Buchinsky FJ, Gennarelli TA, Strome S, et al. Sphenoid sinus mucocele: a rare complication of transsphenoidal hypophysectomy. ENT J. 2001:80(12): 886-888.

9. Hssaine K, Belhoucha B, Rochdi Y, et al. Les mucocèles naso-sinusiennes: à propos de 32 cas. Revue de Stomatologie, de Chirurgie Maxillo-faciale et de Chirurgie Orale. 2016 ; 117(1): :11-14

10. Alamia F, Benchekrouna N, Berdaouia N. El, Oumelalb J, Berrahoa A. Mucocèle sphénoïdale bilatérale révélée par une paralysie du nerf abducens : à propos d'un cas, J Français Ophtalmol. 2013 ; 36 :87-91

11. Lui YW, Dasari SB, Young RJ. Sphenoid 
masses in children: radiologic differentia diagnosis with pathologic correlation. Am J Neuroradiol. 2011; 32(4):617-26

12. Komotar RJ, Burger PC, Carson BS, et al. Pilocytic and pilomyxoid hypothalamic/ chiasmatic astrocytomas. Neurosurg. 2004;54:72-9

13. Clert V, Goujon J, Kauffmman-Lacroix C, et al. Sinusite sphénoïdale fongique non invasive: du diagnostic à la prise en charge. Notre expérience depuis 25 ans. Ann franc Oto-rhino-laryngol Pathol Cervico-faciale. 2014; 131 (4): A95.
14. Arnavielle S, Vignal-Clermont C, Galatoire $\mathrm{O}$, et al. Neuropathie optique compressive liée à une mucocèle de l'apophyse clinoïde antérieure. J Français Ophtalmol. 2010 33(3): 208. e1-208. e6.

\section{Ndongo Pilor}

Fann University Hospital Center

Cheikh Anta Diop University

Dakar

Senegal

Tel: +221775635500

E-mail:ndongopilor@gmail.com

ISSN: 2589-5613 / @2020 The Author(s). This work is licensed under a Creative Commons Attribution 4.0 International License. The images or other third party material in this article are included in the article's Creative Commons license, unless indicated otherwise in the credit line; if the material is not included under the Creative Commons license, users will need to obtain permission from the license holder to reproduce the material. To view a copy of this license, visit http://creativecommons.org/licenses/by/4.0/ 